\title{
WILEY-VCH
}

\section{Enhanced methanol electro-oxidation activity of nanoclustered gold}

\author{
Anupam Yadav, * Yejun Li, Ting-Wei Liao, Kuo-Juei Hu, Jeroen E. Scheerder, Olga V.
} Safonova, Tibor Höltzl, Ewald Janssens, Didier Grandjean, * and Peter Lievens*

Anupam Yadav, Dr. Ting-Wei Liao, Dr. Kuo-Juei Hu, Dr. Jeroen E. Scheerder, Prof. Ewald Janssens, Dr. Didier Grandjean, Prof. Peter Lievens

Quantum Solid-State Physics, Department of Physics and Astronomy, KU Leuven, Celestijnenlaan 200D, Leuven 3001, Belgium

Dr. Yejun Li

Hunan Key Laboratory of Super Microstructure and Ultrafast Process, School of Physics and Electronics, Central South University, Changsha, Hunan 410083, China

Dr. Olga V. Safonova

Paul Scherrer Institute, Villigen PSI 5232, Switzerland

Dr. Tibor Höltzl

Furukawa Electric Institute of Technology, Budapest 1158, Hungary and

MTA-BME Computation Driven Chemistry Research Group and Department of Inorganic and Analytical Chemistry, Budapest University of Technology and Economics, Budapest 1111, Hungary

E-mail: anupam.yadav@kuleuven.be, didier.grandjean@kuleuven.be, peter.lievens@kuleuven.be

Keywords: gas phase clusters, cluster beam deposition, gold nanoparticles, methanol oxidation fuel cells, structure -property correlations, gold electrocatalysis

\begin{abstract}
Size-selected $3 \mathrm{~nm}$ gas phase Au clusters dispersed by cluster beam deposition on a conducting fluorine-doped tin oxide template show strong enhancement in mass activity for the methanol electro-oxidation reaction compared to previously reported nanostructured gold electrodes. Density functional theory based modelling on the corresponding $\mathrm{Au}$ clusters guided by experiments attributes this high methanol electro-oxidation activity to the high density of exposed under-coordinated Au atoms at their faceted surface. In the description of the activity trends, vertices and edges are the most active sites due to their favorable $\mathrm{CO}$ and $\mathrm{OH}$ adsorption energies. The faceted structures occurring in this size range, partly preserved upon deposition, may also prevent destructive restructuring during the oxidation-reduction cycle. These results
\end{abstract}




\section{WILEY-VCH}

highlight the benefits of using cluster beam deposition in fine-tuning material properties on the nanoscale and designing high-performance fuel cell electrodes with less material usage.

\section{Introduction}

Direct Methanol Fuel Cell (DMFC) ${ }^{[1]}$ is a rapidly emerging clean energy technology that enables the direct conversion of the chemical energy stored in methanol fuel to electricity. ${ }^{[2]}$ However, its widespread commercialization is currently hindered by an extensive usage of precious noble metals as catalyst in order to drive high methanol consumption and energy conversion efficiency. Therefore, reducing their usage yet maintaining favorable electrochemical activities becomes necessary for any practical energy harvesting application of DMFCs. ${ }^{[3]}$

Another challenge is to maintain good catalyst stability at low loadings under DMFC operating conditions. ${ }^{[4]}$ For example, Pt is strongly poisoned by the accumulation of the methanol electrooxidation (MEO) reaction residues such as $\mathrm{COH}$ and $\mathrm{CO}$ on its surface, compromising the device durability. ${ }^{[5]}$ Switching from an acid electrolyte to an alkaline one and/or making combinations with oxophilic components enhances Pt activity, given that the presence of adsorbed $\mathrm{OH}$ accelerates the $\mathrm{CO}$ oxidation step. ${ }^{[6]}$ However, such aqueous conditions corrode Pt considerably over time and potentially deteriorate its overall performance. ${ }^{[7,8]}$

Developing a non-Pt electrocatalyst based on $\mathrm{Au}$ that features good activity, tolerance to intermediate carbon residue poisoning, and stability under alkaline conditions is also a promising strategy.$^{[9,10,11]}$ However, the inefficient kinetics of bulk Au MEO catalysts hinders their practical applications in DMFCs. ${ }^{[12-14]}$ In contrast, gold nanoparticles (NPs) supported on polyaniline $(\mathrm{PANI})^{[15]}$ and activated carbon $(\mathrm{Au} / \mathrm{C})$ have demonstrated a remarkable activity in MEO reaction, ${ }^{[10,16]}$ as well as in reduction of carbon dioxide and oxygen evolution reaction (OER). ${ }^{[17,18]}$ Poorly active in its bulk form, Au in the form of NPs and clusters below $6 \mathrm{~nm}$ in 


\section{WILEY-VCH}

73 diameter exhibit indeed an extraordinary high catalytic activity for numerous oxidation and

74 reduction (electro)catalytic reactions. ${ }^{[19,20,21]} \mathrm{CO}$ oxidation reaction over $\mathrm{TiO}_{2}$ supported $\mathrm{Au}$ clusters was found to be highly dependent on size of the Au clusters with a maximum activity occurring at $3.2 \mathrm{~nm} \cdot{ }^{[22]}$ Similar size effects have been demonstrated for Au NPs used as electrocatalyst for the oxygen reduction reaction (ORR), where the activity also reaches a maximum for a particle size around $3 \mathrm{~nm} \cdot{ }^{[23,24]}$

Among the numerous effects at the origin of the unusual catalytic properties of nanosized $\mathrm{Au}$ such as the preparation method and activation procedure, the Au layer thickness, the interaction with the support material and the intrinsic cluster strain, the availability of many undercoordinated Au atoms on the small particles is by far the dominant one. ${ }^{[19,25]}$ Most of the surface $\mathrm{Au}$ atoms in small particles are likely to participate in chemisorption of the reactants, the propensity of which depends on the extent of coordination of the Au atom(s) acting as adsorption site. ${ }^{[26]}$ Both $\mathrm{O}$ and $\mathrm{CO}$ binding energies are lowered (stronger bonding) by up to ca. $1 \mathrm{eV}$ going from 9-fold coordinated $\mathrm{Au}$ atoms on $\mathrm{Au}(111)$ faces to 4-fold coordinated $\mathrm{Au}$ atoms in $\mathrm{Au}_{10}$ clusters. ${ }^{[19]}$ This directly results from an upshift towards the Fermi level of the d states of the low coordinated $\mathrm{Au}$ atoms enabling strong interaction of those $\mathrm{d}$ states with the $\mathrm{O} 2 \mathrm{p}$ valence states. $^{[19,27]}$

Designing higher performance Au catalysts requires increasing the concentration of undercoordinated sites of relatively low coordination number at the surface of gold. This could be achieved by decreasing the Au particle size,${ }^{[19]}$ but also by controlling the particle shape and crystalline structure. ${ }^{[28]}$ Conventional chemical preparation methods have demonstrated only modest abilities to control the structural properties of Au NPs. Highly dispersed Au catalysts prepared by dc sputtering, deposition-precipitation, gas-phase, and liquid-phase grafting of organo-gold complexes using an $\mathrm{Al}_{2} \mathrm{O}_{3}, \mathrm{SiO}_{2}$, or $\mathrm{TiO}_{2}$ support with relative control over $\mathrm{Au}$ NPs mean diameter and shape exhibit higher overall catalytic activities compared with those prepared by impregnation. ${ }^{[29]}$ Although preformed size-selected Au colloids allow for a better 


\section{WILEY-VCH}

definition of the particle size, the presence of protecting ligands is generally limiting their catalytic activity and preventing the formation of a crystalline faceted surface. ${ }^{[30]}$ Moreover, removal of the ligands to obtain catalytically active "naked particles" requires additional, possibly destructive, activation treatments. ${ }^{[21]}$ Direct electrodeposition of large Au NPs on the electrode surface ${ }^{[15]}$ was also reported but only limited size selection was obtained.

Cluster beam deposition (CBD) combined with mass selection is a physical method that allows production of naked Au clusters highly controlled in terms of particle size, deposition energy, and coverage (average density) on any type of substrate surface. ${ }^{[31,32]}$ Such Au clusters as produced and deposited by CBD are free of surfactant molecules and generally possess welldefined atomic configurations specific to the cluster size and that can differ significantly from the bulk, ${ }^{[32]}$ as demonstrated for size-selected $\mathrm{Au}_{20},{ }^{[33]} \mathrm{Au}_{55},{ }^{[34]} \mathrm{Au}_{309},{ }^{[35]}$ and $\mathrm{Au}_{923}{ }^{[36]}$. Besides, CBD synthesis can be adjusted in a way that most of these clusters possess highly faceted structures with a high concentration of edge and vertex surface atom sites and a limited fraction of amorphous structures (below $22 \%$ in a study of $\mathrm{Au}_{923}{ }^{[32]}$ The use of these well-defined $\mathrm{Au}$ clusters, produced in the gas phase and beam-deposited subsequently, as catalysts may contribute to obtaining a clear understanding of nanocatalysis at atomic or molecular scale that still remains elusive. ${ }^{[30,37]}$ In the remainder of this paper we refer to these clusters as NC. NC stands for nanoclusters, where nano refers to the size of the particles and cluster refers to the gas phase cluster beam production methodology used.

In this paper, we describe a highly active DMFC anode for the MEO reaction based on dispersed $3 \mathrm{~nm}$ diameter Au NCs, corresponding to the optimal activity size reported for (electro)catalytic reactions. We demonstrate that $\mathrm{CBD}$ synthesis of size-selected Au clusters offers efficient and stable utilization of active metal. ${ }^{[23]}{ }^{[38]}$ The structural and electrochemical properties of deposited $\mathrm{Au}$ NCs were evaluated by a combination of aberration-corrected Scanning Transmission Electron Microscopy (STEM) employing High Angle Annular Dark Field (HAADF) detectors, X-ray Absorption Fine Structure (XAFS) spectroscopy, Scanning Electron 


\section{WILEY-VCH}

125 Microscopy (SEM) and Cyclic Voltammetry (CV) techniques. Au NCs on fluorine-doped tin oxide (FTO) demonstrate a strongly enhanced MEO activity in comparison to Au colloids synthesized by wet chemistry and drop-casted on FTO supports. The intrinsic activity of the naked Au cluster is rationalized using Density Functional Theory (DFT). Calculations based on model clusters of this size allow achieving a comprehensive understanding of the role of different Au NCs surface sites in the MEO process.

\section{Main Text}

A home built magnetron sputtering CBD setup was used for producing Au clusters. Following deposition their structural properties were characterized in detail by various methods (Figure 1). In brief, Au clusters were synthesized by condensation of Ar sputtered Au atoms from a bulk $\mathrm{Au}$ target in a controlled atmosphere of $\mathrm{Ar}$ and $\mathrm{He}$, while the condensation chamber was cooled to liquid nitrogen temperatures. Preformed cationic Au clusters were size-filtered during flight using an orthogonal ion bender and subsequently deposited on either carbon TEM grids, boron doped amorphous $\mathrm{SiO}_{2} / \mathrm{Si}$ (100) wafers, or FTO supports held at room temperature under UHV conditions. Precise tuning of the deposition energy and the particle density on the surface was achieved by adjusting the substrate bias voltage, ensuring soft landing of isolated clusters with a kinetic energy of less than $0.2 \mathrm{eV}$ per atom, and monitoring the current from the beam of charged clusters, respectively. The surface coverage was kept below $20 \%$ of a monolayer of size-selected $\mathrm{Au}$ NCs. As will be discussed further on, under these conditions cluster fragmentation and agglomeration is limited. Unlike wet chemistry, no further calcination or activation steps are required after deposition. 


\section{WILEY-VCH}

a)

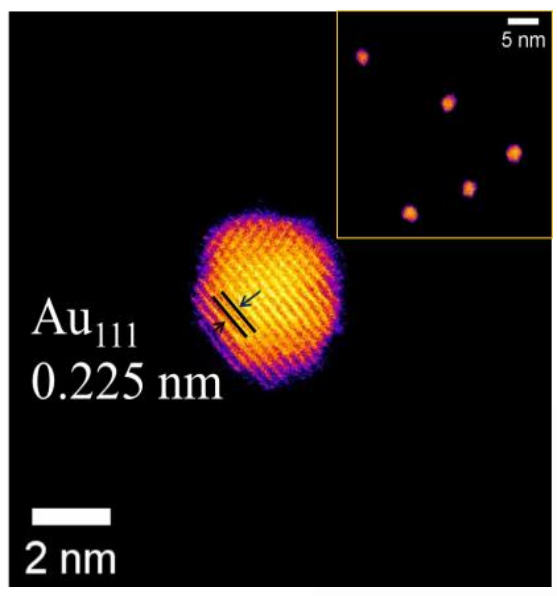

b)

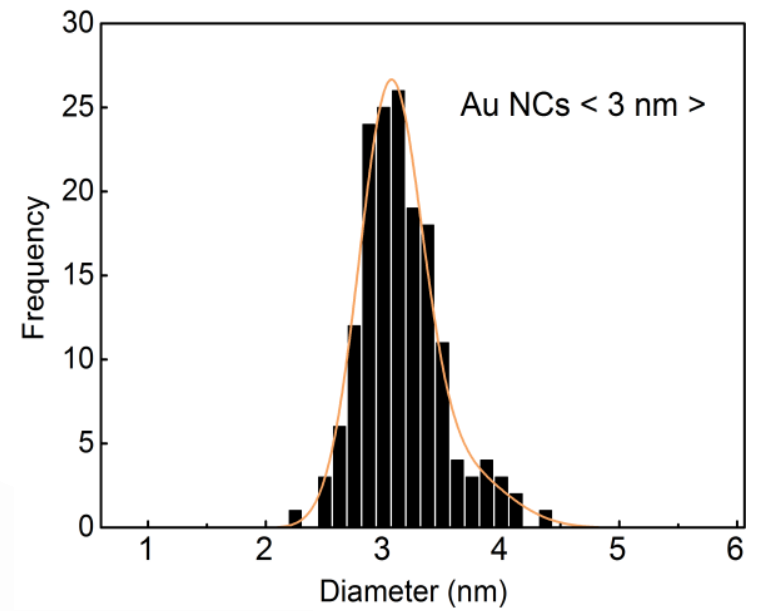

Clusters Size Selection

d)

c)

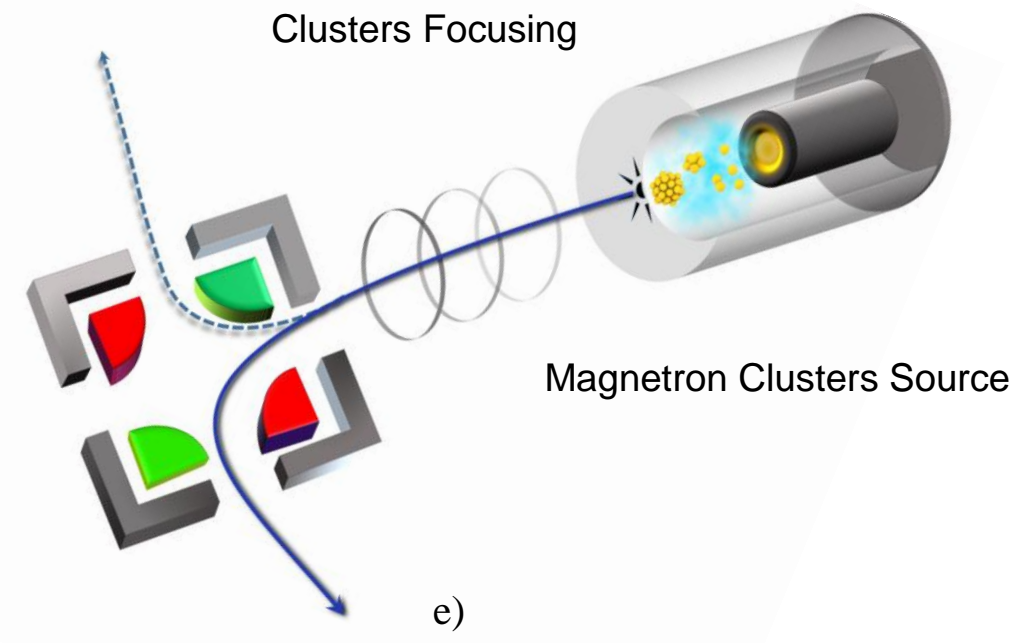

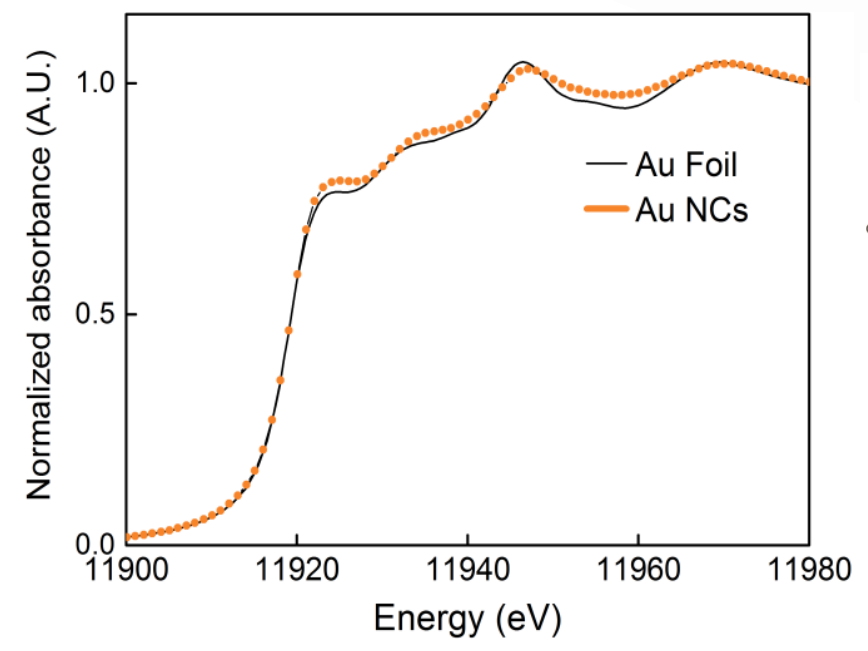

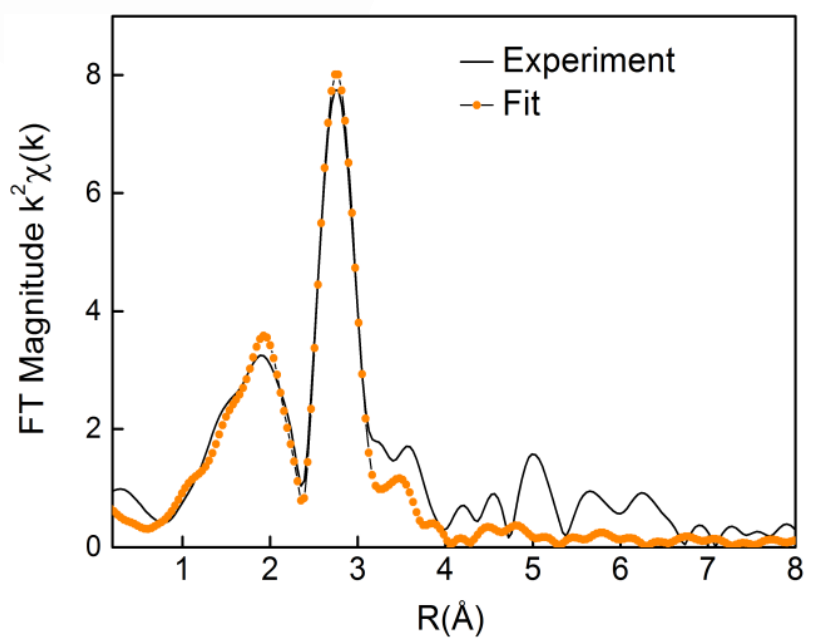

Figure 1: Synthesis and atomic scale structural properties of Au NCs. (a) Sub-Ångström resolution STEM-HAADF images of Au NCs. (b) Histogram distribution of Au NCs diameter. (c) Schematic illustration of magnetron CBD technology. (d) Fluorescence detected $\mathrm{Au} \mathrm{L}_{3}$ XANES of Au NCs on a $\mathrm{SiO}_{2} / \mathrm{Si}(100)$ wafer compared to a reference Au foil. (e) Best fit of Au NCs Fourier transform of $\mathrm{k}^{2}$ weighted EXAFS. 


\section{WILEY-VCH}

148 A representative STEM-HAADF image of a surfactant-free Au NC with sub-Ångström

149 resolution is presented together with the histogram of Au NCs size distribution in Figures 1a

150 and $1 \mathrm{~b}$, respectively. The STEM image shows that the preformed Au clusters remain intact

151 upon deposition, presenting a sharp narrow particle size distribution on the surface. A mean

152 diameter of $\mathrm{Au}$ NCs of $3.0 \mathrm{~nm}$ with a standard deviation of $0.3 \mathrm{~nm}$ was obtained by measuring

153 over 160 NCs. The shoulder in the distribution at $4 \mathrm{~nm}$ corresponds to a fraction of about $10 \%$

154 of doubly charged clusters of twice the mass of the main peak in the distribution that are selected

155 together with the singly charged smaller clusters by the quadrupole bender. Detailed STEM

156 analysis indicates that individual Au NCs have ordered faceted geometries, with identifiable

157 lattice fringes matching the $\mathrm{Au}(111)$ atomic plane configuration (Figure 1a and S1). This is in

158 line with an earlier study of well-defined Au923 prepared by CBD, whose population is

159 composed of a mixture of icosahedral (Ih), decahedral (Dh), and face-centered cubic (FCC)

160 structural motifs. ${ }^{[32]}$ The individual fractions of aforementioned structures depend on the

161 synthesis parameters. ${ }^{[32]}$

162 Electron microcopy characterization was complemented by the determination of the average

163 structural and electronic properties of $\mathrm{Au}$ NCs deposited on a silicon wafer using XAFS

164 spectroscopy. The Au L3-edge XANES (X-ray Absorption Near Edge Structure) of the Au NCs shows damped oscillations compared to reference Au metal foil, confirming their nanosize (Figure 1d). The edge position overlaps with that of Au foil confirming the absence of isolated cationic Au species on the support. The modest white line intensity observed has been ascribed to the completely filled d-orbitals of metallic Au. ${ }^{[39]}$ The combined XANES edge position and

169 white-line intensity thereby provides direct evidence that the Au NCs are predominantly composed of Au species in zero-valence state. The best fit of the Fourier transform of the $\mathrm{k}^{2}-$

171 weighted Au L 3 edge EXAFS (Extended X-ray Absorption Fine Structure) (Figure S2) and the

172 corresponding structural results are presented in Figure 1e and Table S1, respectively. The first

173 shell coordination number $(\mathrm{CN})$ is reduced to 10.3 versus 12 in a bulk Au foil, highlighting the 


\section{WILEY-VCH}

174 large fraction of surface atoms in the Au NCs. This value gives a theoretical diameter of $(2.8 \pm$

$1750.8) \mathrm{nm}$ fully in agreement with the STEM results. ${ }^{[40]}$ The Au-Au bond distance of $2.85 \AA$ of

176 the first coordination shell corresponds to a contraction of about $1 \%$ compared to a bulk Au foil

$177(2.88 \AA)$, an effect that is generally observed in nanosize gold. ${ }^{[41]}$ EXAFS analysis confirms

178 that the gaseous Au clusters retain their three dimensional shape upon deposition resulting from

179 soft-landing the clusters on the support and limited interaction with the surface.

180 Finally, the nanotextured surface of bare FTO (Figure S3) and that modified by Au depositions

181 was characterized by high resolution SEM. Images of FTO electrodes modified by deposition

182 of gaseous Au clusters using CBD and by colloidal Au NPs of similar size (Figure S4) prepared

183 via a wet chemistry route, used as control sample, are presented in Figure 2. The Au NCs,

184 identified as bright speckles, are deposited homogeneously and highly dispersed on the

185 electrode surface (Figure 2a). The global gold metal loading at the surface of the Au NCs

186 modified FTO electrode is $425 \mathrm{ng} \mathrm{cm}^{-2}$, as determined by Rutherford Backscattering

187 Spectroscopy (RBS). It is matching the coverage estimate of $20 \%$ of a close packed monolayer

188 of $\mathrm{Au}$ NCs on the FTO surface derived from monitoring the NCs current during deposition.

189 Unlike Au NCs, drop-casted Au colloids were not stable against agglomeration. The sample

190 prepared from Au colloids has a metal loading of $21 \mu \mathrm{g} \mathrm{cm}^{-2}$ (Figure $2 \mathrm{~b}$ ).
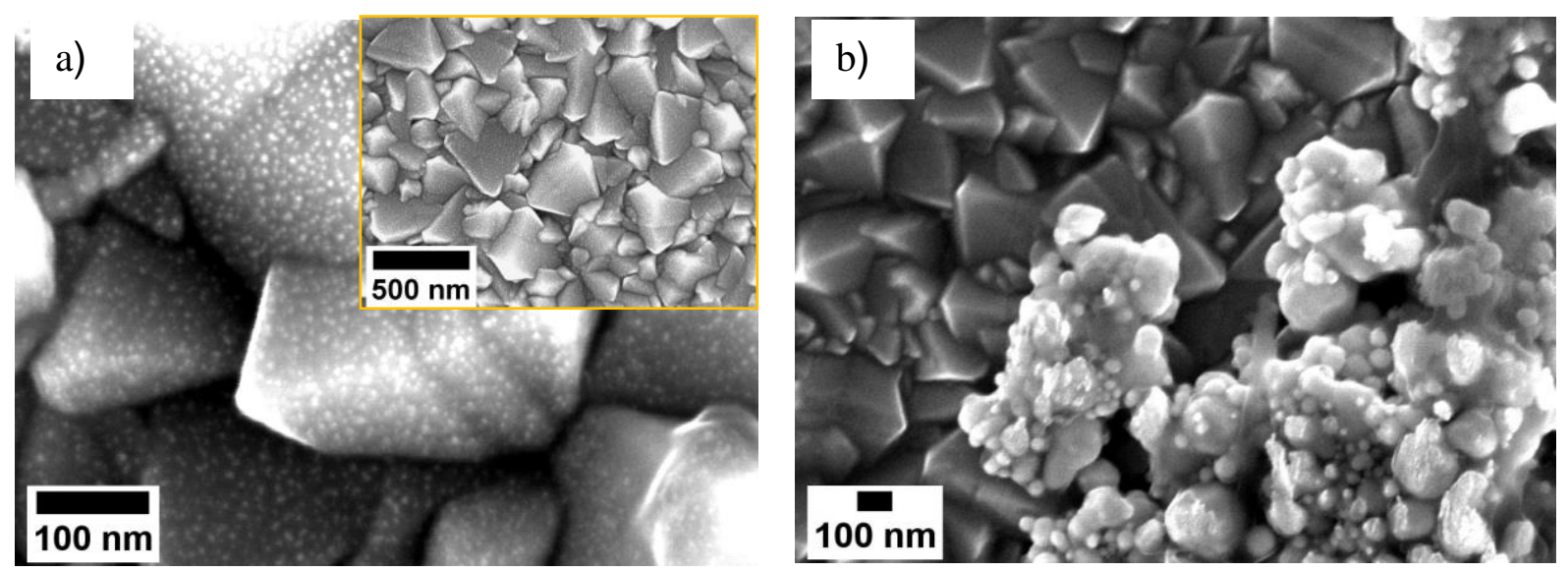

Figure 2: High Resolution SEM images of (a) Au NCs modified FTO and (b) colloidal Au modified FTO. The inset image in (a) shows the global view of deposited Au NCs. 


\section{WILEY-VCH}

191 The catalytic activity of the as-synthesized Au NCs modified FTO towards MEO was evaluated

192 by measuring their $\mathrm{CV}$ curves in a $0.5 \mathrm{M} \mathrm{KOH}$ solution at a scan rate of $20 \mathrm{mV} \mathrm{s}^{-1}$, as shown

193 in Figure 3. In the methanol-free $\mathrm{KOH}$ solution the bare FTO electrode is inert at potentials

194 below $500 \mathrm{mV}$, in line with the requirement of minimum capacitive currents from the support
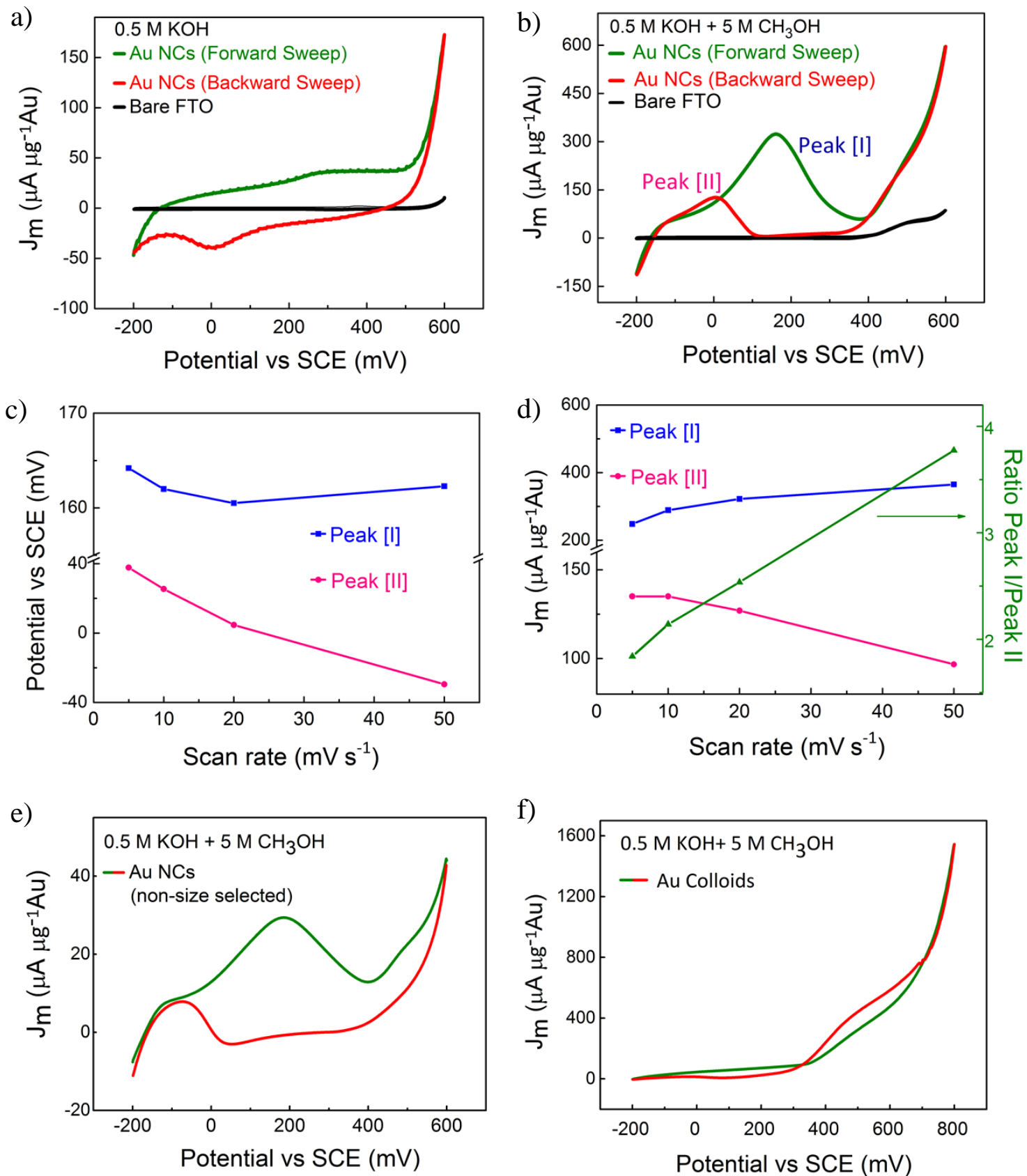

Figure 3: MEO activity of 3nm Au NCs at scanning rate of $20 \mathrm{mV} \mathrm{s}^{-1}$. Cyclic scans of bare FTO and Au NCs modified FTO under (a) $0.5 \mathrm{M} \mathrm{KOH}$ and (b) $0.5 \mathrm{M} \mathrm{KOH}$ and $5 \mathrm{M} \mathrm{CH}_{3} \mathrm{OH}$. c) MEO peak potentials versus scan rate; (d) MEO peak current densities and their ratio versus scan rate. MEO activity of control Au samples (e) non size-selected gaseous Au NCs and (f) colloidal Au nanoparticles. 


\section{WILEY-VCH}

195 (Figure 3a). CV of Au NCs modified FTO in the methanol-free KOH solution consists of four

196 distinctive regions (Figure 3a). From 70 to $130 \mathrm{mV} \mathrm{Au}-\mathrm{OH}_{\mathrm{ads}}{ }^{(1-\lambda)-}$ is formed at the surface of

$197 \mathrm{Au} \mathrm{NCs}{ }^{[10,42]}$ according to $\mathrm{Au}+\mathrm{OH}^{-} \rightarrow \mathrm{Au}_{-} \mathrm{OH}_{\mathrm{ads}}(1-\lambda)-+\lambda \mathrm{e}-$, where ads denotes chemical

198 adsorbed species on the clusters. The charge-transfer coefficient $\lambda$ varies between 0 and $1 .{ }^{[14,43]}$

199 In the second region $(130-400 \mathrm{mV})$ the surface of the Au NCs is oxidized to form gold

200 (hydro)oxide species with Faradaic current flowing through the interface. ${ }^{[44]}$ From 400 to 600

$201 \mathrm{mV}$, a compact gold (hydro)oxide monolayer is generally formed ${ }^{[11]}$ that is electrochemically

202 reduced to form a cathodic current peak at ca. $0 \mathrm{mV}$ during the negative scan. ${ }^{[11,14,45]}$ In the last

203 region around $600 \mathrm{mV}$ the large current increase is likely due to the decomposition of the

204 electrolyte at high potentials resulting in the oxygen evolution reaction (OER). ${ }^{[46]}$ The much

205 more limited current increase observed in the same region for bare FTO highlights the high

206 catalytic activity of Au NCs towards OER.

207 Upon addition of methanol (5M), the CV of Au NCs modified FTO in the KOH solution 208 exhibits two clear peaks related to the MEO process assigned as Peak I and II in the forward 209 and backward potential scan, respectively (Figure 3b). The low curve region of Peak I at 0.0 $210 \mathrm{mV}$ with an amplitude of $128 \mu \mathrm{A} \mu \mathrm{g}^{-1}$ corresponds to the onset of the oxidation of methanol

211 into formate via a four-electron transfer according to reaction (1): ${ }^{[14,47]} \mathrm{CH}_{3} \mathrm{OH}+5 \mathrm{OH}^{-} \rightarrow$

$212 \mathrm{HCOO}^{-}+4 \mathrm{H}_{2} \mathrm{O}+4 \mathrm{e}^{-}$, whose intensity is limited by the low concentration of $\mathrm{Au}-\mathrm{OH}_{\mathrm{ads}}(1-\lambda)-$

213 formed on the gold surface atoms. As the potential increases the more concentrated $\mathrm{Au}-\mathrm{OH}_{\mathrm{ads}}{ }^{(1-}$

$214^{\text {2)- }}$ oxidize methanol into formate with enhanced efficiency forming the intense Peak I at 160 $215 \mathrm{mV} \cdot{ }^{[11,12,14,47,48]}$ This peak that appears before the formation of a gold (hydro)oxide represents

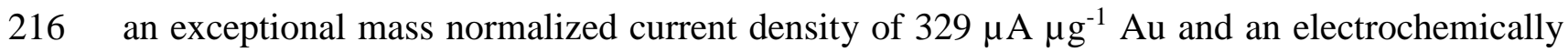
217 active surface area (ECSA) normalized current density of $1.85 \mathrm{~mA} \mathrm{~cm}^{-2}$ despite Au loading in 218 the nanogram range. The current density then decreases sharply due to the formation of a 219 (hydro)gold oxide monolayer on the surface of Au NCs that restrains the MEO by decreasing 


\section{WILEY-VCH}

220 the number of available $\mathrm{OH}_{\text {ads. }}{ }^{[16]}$ Peak I is followed, after the exchange between $\mathrm{OH}^{-}$and $\mathrm{O}$ 221 species ("turnover") by an exponential burst in the current output from $400 \mathrm{mV}$ onwards. It 222 corresponds to the methanol oxidation into carbonates by a compact gold (hydro)oxide 223 monolayer formed at these high potentials via a six-electron transfer reaction $(2):^{[12,14,48]}$ $224 \mathrm{CH}_{3} \mathrm{OH}+8 \mathrm{OH}^{-} \rightarrow \mathrm{CO}_{3}{ }^{2-}+6 \mathrm{H}_{2} \mathrm{O}+6 \mathrm{e}^{-}$. In the backward scan, no hysteresis is observed down to $400 \mathrm{mV}$ suggesting that the extent of the gold (hydro)oxide formed is limited in this high potential range. This is further confirmed by the absence of a electrochemical reduction peak just above $0 \mathrm{~V}$ and the early onset of Peak II at $100 \mathrm{mV}$ once the Au NC surface is free of $\mathrm{OH}_{\mathrm{ads}}$.

228 Similarly a slightly positive hysteresis is observed between 0 and $-200 \mathrm{mV}$ suggesting that the 229 Au NCs surfaces are not degraded compared to those observed in the first forward scan. This 230 indicates a fully reversible oxidation-reduction of the Au NC surfaces during the CV.

231 The dynamics of the methanol oxidation reaction on Au NCs estimated by adjusting the scan 232 rate (Figure S5) is summarized in Figures 3c and d. Upon increasing scan rates the potential of 233 Peak I remains constant, while Peak II shifts towards lower potentials. Peak I current increases 234 and is proportional to the square root of the scan rate, suggesting that the oxidation of methanol 235 is a Faradic process. ${ }^{[49]}$ The Peak II current is higher at low scan rates, in stark contrast to the 236 typical trend seen in surface confined or diffusion controlled voltammetry. ${ }^{[50,51]}$ This is due to 237 the significant removal of $\mathrm{OH}^{-}$by methanol from the Au NCs surface for the low scan rates. 238 This is further manifested by the shape of the $\mathrm{CV}$ experiment at $50 \mathrm{mV} \mathrm{s}^{-1}$ in which the 239 hysteresis builds up between the forward and backward scans above $400 \mathrm{mV}$, and the small 240 reduction peak is observed at $100 \mathrm{mV}$, causing the late onset of Peak II.

241 The MEO activity of Au NCs was compared to two similar control electrodes: i) FTO 242 supporting sub $5 \mathrm{~nm}$ non size-selected gaseous Au clusters prepared by an alternative laser 243 ablation CBD source (Figure S6 and 3e) and ii) FTO supporting drop-casted Au colloids 244 prepared by wet chemistry (Figure S4 and 3f). Size-selected $3 \mathrm{~nm}$ Au NCs show by far the best 


\section{WILEY-VCH}

245 electrochemical properties with a much higher activity towards MEO than both the non sizeselected CBD Au NCs and the chemically prepared drop-casted Au colloids.

247 Mass activity of sub $5 \mathrm{~nm}$ non size-selected Au NCs is 11 times lower than that of the sizeselected $3 \mathrm{~nm}$ Au NCs. Moreover a five-time increase of the non-size selected Au NCs loading produces only less than a doubling of the mass activity $\left(29 \mu \mathrm{A} \mathrm{gg}^{-1} \mathrm{Au}\right.$ to $52 \mu \mathrm{A} \mathrm{g} \mathrm{g}^{-1} \mathrm{Au}$, Figure S7). In contrast with size-selected Au NCs, the strong hysteresis between forward and backward 251 scans occurring above $400 \mathrm{mV}$ indicates a marked oxidation of the NC surface that is accompanied with a marked reduction peak at $0 \mathrm{~V}$. At the highest scan rate of $50 \mathrm{mVs}^{-1}$, the hysteresis above $400 \mathrm{mV}$ is found to be more pronounced indicating stronger oxidation of the $\mathrm{Au}$ NCs surface. Unlike low scan rates, a further drop in the Faradic current is observed below $-100 \mathrm{mV}$ during the backward scan demonstrating that the original activity in the onset of fourelectron oxidation has decreased. This suggests that a substantial number of under-coordinated active sites has been lost in the $\mathrm{CV}$, either by an incomplete reduction and/or a restructuring of the surface upon reduction highlighting the instability of the non size-selected NCs towards oxidation-reduction cycle. Surface restructuring ${ }^{[44,52]}$ of monocrystalline Au surfaces upon $\mathrm{Au}$ electro-oxidation and subsequent reduction generally promotes a roughening of smooth bulk electrode surfaces due to the development of monoatomic pits during the oxide reduction. ${ }^{[53]}$ At high applied potentials it may even become destructive if a significant 'turnover process' occurs. ${ }^{[52,54]}$

Finally, chemically prepared Au colloid electrodes (Figure 3f) did not show any MEO activity peaks (Peak I and II) despite the Au loading being 50 times higher $\left(21 \mu \mathrm{g} \mathrm{cm}^{-2}\right)$ than that of $\mathrm{Au}$ NCs samples. This may be attributed to a significant decrease in the ECSA caused by agglomeration of NPs on the FTO surface (Figure 2b) as well as to the presence of cetyltrimethylammonium bromide (CTAB) surfactant remaining at the Au surface that may both limit the access of the reactants to the active sites and hinder their formation at the $\mathrm{Au}$ metal surfaces. The detrimental role of surfactant passivating the surface of Au NPs on their 


\section{WILEY-VCH}

271 catalytic activity is supported by the absence of MEO activity (Figure S9) on a more dispersed 272 test sample of drop-casted colloidal Au NPs intentionally left unwashed on the FTO surface 273 (SEM image presented in Figure S8).

274 The stability and electrochemical activity of FTO modified with Au NCs and colloidal Au NPs 275 were measured by chronoamperometry. The electrodes were held at a potential of $0.158 \mathrm{~V}$ for $276400 \mathrm{~s}$ in stationary electrolytes $\left(0.5 \mathrm{M} \mathrm{KOH}+5 \mathrm{M} \mathrm{CH}_{3} \mathrm{OH}\right)$. The temporal evolution of the $\mathrm{Au}$ 277 mass normalized current (Figure S10) demonstrates, in both systems, a drop in the initial 278 currents followed by a tendency to approach a limiting value. The relatively longer time taken 279 by Au NCs to reach stable currents reflects the higher stability of Au NCs compared to Au 280 colloids. At 400s, the Au mass normalized currents measured for Au NCs and colloidal Au NPs 281 are $116.5 \mu \mathrm{A} \mu \mathrm{g}^{-1} \mathrm{Au}$ and $0.6 \mu \mathrm{A} \mu \mathrm{g}^{-1} \mathrm{Au}$, respectively. This high rate further confirms the 282 outstanding catalytic performance and relative stability over this timescale of Au NCs towards methanol oxidation. Compared to the mass activity of chemically prepared nanostructured $\mathrm{Au}$ catalysts reported in literature, for example, Au NPs supported on carbon $\left(48.6 \mathrm{~mA} \cdot \mathrm{mg}^{-1}\right.$

$\mathrm{Au}),{ }^{[16]} \mathrm{AuNi} / \mathrm{C}\left(52.9 \mathrm{~mA} \mathrm{mg}^{-1} \mathrm{Au}\right),{ }^{[55]}$ and hollow nanoporous gold and solid $\mathrm{Au}$ (equivalent

to $42.5 \mathrm{~mA} \mathrm{mg}^{-1} \mathrm{Au}$ at $\left.5 \mathrm{M} \mathrm{MeOH}\right),{ }^{[56]}$ the $\mathrm{Au} \mathrm{NCs}$ catalyst presents a 6 to 7 times enhanced activity under identical methanol electro-oxidation conditions. ${ }^{[51]}$ Pairing Au with other elements and/or active supports ${ }^{[57]}$ may improve the mass activity of Au-based NCs further to match that of state-of-the-art Pt/C catalyst that was found 4 times more active under the test conditions used in this work (Figure S11).

\section{Origin of nanoclustered gold catalytic activity enhancement}

To unravel the origin of the superior electrocatalytic properties of Au NCs, the relationship

294 between their physical characteristics and their MEO activity was further investigated by first295 principles calculations. We have computationally synthesized an Au cluster with experimentally known $3 \mathrm{~nm}$ size. The geometric structure of the Au cluster obtained using 


\section{WILEY-VCH}

297 simulated annealing (starting from a Wulff constructed $3 \mathrm{~nm}$ particle consisting of 807 atoms)

298 closely resembles that of the deposited catalyst (see Figure S12 and SI methods section for 299 details). Before characterizing the surface Au sites, the simulated Au807 structure was refined 300 by the ReaxFF force field method. 100 to 200 -atom models centered on the adsorption site 301 within a cut-off distance probed by the $\mathrm{OH}$ binding energy on reference $\mathrm{Au}(111)$ surface (Figure 302 S13) were extracted from the $\mathrm{Au}_{807}$ cluster for further DFT computations. ${ }^{[58]}$ A cut-off distance 303 of $11 \AA$ is selected, large enough to separately describe the on-top and the bridge site with a computational accuracy of $0.06 \mathrm{eV}$.

The computationally synthesized $\mathrm{Au}_{807}$ has a quasi-icosahedral shape with an average coordination of 10.4 in excellent agreement with the EXAFS value (illustrated in Figure S14 and Table S2). The stability of the simulated $\mathrm{Au}_{807}$ quasi-icosahedral structure is in line with

308 previous theoretical simulations, ${ }^{[18,59]}$ and experimental investigations highlighting the 309 occurrence of various structures for this cluster size ${ }^{[32]}$ (Figure S1).

310 Previous studies have demonstrated that the adsorption free energies of $\mathrm{CO}\left(\Delta \mathrm{G}_{\mathrm{CO}}\right)$ and $\mathrm{OH}$ $311\left(\Delta \mathrm{G}_{\mathrm{OH}}\right)$ are good descriptors of MEO reaction. ${ }^{[60,61]}$ Adsorption free energies of all methanol 312 decomposition intermediates binding through carbon or oxygen atoms with various catalytic 313 metal surfaces were shown to scale linearly with $\Delta \mathrm{G}_{\mathrm{CO}}$ or $\Delta \mathrm{G}_{\mathrm{OH}}$, respectively. Moreover, the 314 limiting potential for methanol activation following a clear volcano plot with respect to these 315 variables was reported. ${ }^{[60,61]}$ In line with references ${ }^{[60,61]}$, we based the adsorption free energies 316 of $\mathrm{CO}$ and $\mathrm{OH}$ to those of $\mathrm{CO}_{2(\mathrm{~g})}$ and $\mathrm{H}_{2} \mathrm{O}_{(\mathrm{l})}$ respectively at standard conditions, and apply the 317 Computational Hydrogen Electrode (CHE) model, ${ }^{[62]}$ given that the anodic reaction of the 318 complete methanol oxidation is $\mathrm{CH}_{3} \mathrm{OH}(\mathrm{g})+\mathrm{H}_{2} \mathrm{O}(\mathrm{l}) \rightarrow \mathrm{CO}_{2}(\mathrm{~g})+6 \mathrm{H}^{+}+6 \mathrm{e}^{-}$(see SI methods 319 section for the details). Although the exact values depend slightly on the computational details, 320 the consistent choice of the descriptors makes it possible to compare the computed trends to 321 that in references. ${ }^{[60,61]}$ 


\section{WILEY-VCH}

322 This shows that the low methanol oxidation activity of $\mathrm{Au}(111)$ surface is due to the highly

323 positive $\Delta \mathrm{G}_{\mathrm{CO}}$ and $\Delta \mathrm{G}_{\mathrm{OH}}$ values and their decrease is desirable to reduce the MEO efficiency. ${ }^{[61]}$

324 We directly modelled the interaction of $\mathrm{CO}$ and $\mathrm{OH}$ molecules with a quasi-icosahedral $\mathrm{Au}_{807}$ and a reference octahedral $\mathrm{Au}_{891}$ cluster (Figure S15 and Table S3). The adsorption energies and adsorption free energies of $\mathrm{OH}$ and $\mathrm{CO}$ are computed for several possible adsorption sites and further compared with those on an $\mathrm{Au}(111)$ extended surface (Figure 4).

$\mathrm{CO}$ and $\mathrm{OH}$ adsorption free energies computed at different adsorption sites of the quasiicosahedron $\mathrm{Au}_{807}$ and the octahedron $\mathrm{Au}_{891}$ are generally less positive than those obtained on at the $\mathrm{Au}(111)$ surface (Figure S15). More specifically we find that the $\mathrm{CO}$ and $\mathrm{OH}$ adsorption free energies at the vertices of the $\mathrm{Au}_{807}$ quasi-icosahedron cluster are even less positive than those on the Au891 octahedron cluster with the lowest values close to those of the stepped $\mathrm{Au}(221)$ surface exposing under-coordinated atoms. ${ }^{[61]}$ As the ability of under-coordinated $\mathrm{Au}$ atoms to bind adsorbates is closely related to the barriers for surface reactions, ${ }^{[19]}$ the edges and especially the vertices of Au clusters are expected to be the most active catalytic sites.

In the icosahedral clusters the number of vertex sites is 12 , thus the fraction of undercoordinated surface atoms scales with the decreasing cluster size with respectively $2 \%$ vertex, $21 \%$ edge and $21 \%$ face atoms for $2.5 \mathrm{~nm} \mathrm{Au}_{561}$ and $1 \%$ vertex, $16 \%$ edge and $22 \%$ face atoms for $3 \mathrm{~nm} \mathrm{Au} \mathrm{Au}_{807}$ (Figure S16). Thus, due to a simple geometric scaling the smaller clusters are expected to have larger activity than much larger clusters such as $4.8 \mathrm{~nm} \mathrm{Au}_{3871}$ that features $0.3 \%$ vertex, $7 \%$ edge and $19 \%$ face atoms. Similarly, the fraction of catalytically inactive core atoms is $56 \%$ in $\mathrm{Au}_{561}, 61 \%$ in $\mathrm{Au}_{807}$, and reaches $74 \%$ in $\mathrm{Au}_{3871}$. However, the higher surface to volume ratio of the very small clusters in sub nanometer range leads to higher surface energy, thus a decreased stability, what is demonstrated in Figure S17. Thus, the activity of nanoclustered $\mathrm{Au}$ is determined by the balance between these two effects and the 2-4 $\mathrm{nm}$ size range exhibits a good balance between the relatively high surface site density and the stability. 

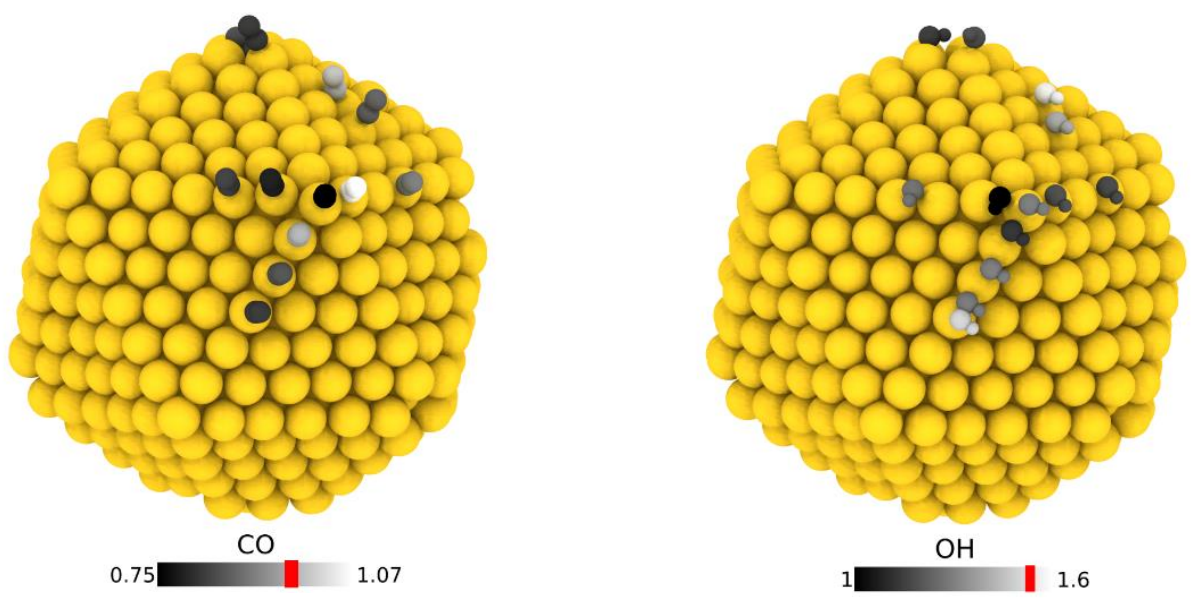

Figure 4: Adsorption sites and the corresponding adsorption free energies of $\mathrm{CO}$ and $\mathrm{OH}^{-}$in $\mathrm{eV}$ at various sites of the $\mathrm{Au}_{807}$ cluster. Each adsorbant represents a separate computation. Reference values, computed for the $\mathrm{Au}(111)$ surface, are marked in red on the scale bars.

347 We then attribute the exceptional catalytic performance of size-selected 3nm Au NCs deposited 348 on FTO electrodes to the high density of highly active under-coordinated surface atoms compared to the total number of atoms optimal at this cluster size combined to an improved stability towards oxidation of the cluster's faceted structure. The decrease of the adsorption free energy at neutral potential at the vertex sites of $\mathrm{Au}_{807}$ compared to that on $\mathrm{Au}(111)$ surface is even more remarkable for $\mathrm{OH}(0.6 \mathrm{eV}$ from $1 \mathrm{eV}$ at cluster vertices to $1.6 \mathrm{eV}$ at $\mathrm{Au}(111)$ surface) than for CO. Similar but weaker effects are also obtained for the cluster edge atoms

354 that separate two facets. Decrease in adsorption free energy of $\mathrm{OH}$ is expected to increase the 355 amount of fractional charge transferred $(\lambda \mathrm{e}-)$, giving rise to a more polarized $\mathrm{Au}-\mathrm{OH}_{\mathrm{ads}}(1-\lambda)-$ 356 surface. As a result, the interaction between $\mathrm{Au}-\mathrm{OH}_{\mathrm{ads}}{ }^{(1-\lambda)-}$ and methanol is expected to 357 strengthen, leading to a high MEO activity. ${ }^{[63]}$ This enhanced interaction of methanol with the 358 under-coordinated sites of Au NCs is unhampered by the water molecules, as the surface charge 359 of $\mathrm{Au}$ is negative in the potential region of $-150-400 \mathrm{mV} \cdot{ }^{[10]}$

360 The importance of selecting the optimal Au cluster size is demonstrated by the substantial lower 361 activity of the control electrode produced by depositing non size-selected sub $5 \mathrm{~nm}$ Au clusters 


\section{WILEY-VCH}

362 that is comparable to that reported for other Au NPs.. This is attributed to a lower density of under-coordinated atoms resulting from the important atomic fraction forming the large clusters (4 to $5 \mathrm{~nm}$ ) as seen on the atom-weighted distribution (Figure S6c). The mixture of cluster sizes ranging from few atom clusters to larger $5 \mathrm{~nm}$ structures is also expected to favour a loss of ECSA through Ostwald ripening, agglomeration and/or more severe corrosion of the oligomeric clusters. ${ }^{[8,64]}$ On the other hand, remarkable stability of size-selected Au NCs faceted structures versus non size-selected NCs upon oxidation-reduction at $20 \mathrm{mVs}^{-1}$ scan rate is highlighted, as discussed above, both by the absence of hysteresis above $400 \mathrm{mV}$ and of a electrochemical reduction peak in the backward scan. The absence of activity of chemical Au colloids is likely the consequence of the presence of ligands, which are (1) hindering the crystallization of a faceted Au structure (2) preventing access for the reactants to the Au surface sites. This clearly demonstrates the benefit of using CBD technology over chemical preparations. Ligand removal by high temperature annealing that favours their sintering is likely inadequate to reproduce the highly symmetrical crystal structures of deposited Au clusters.

The production of this novel highly active Au electrocatalyst for MEO has been made possible by the gas-phase CBD technology that allows a precise selection of cluster sizes not always accessible by conventional chemistry yielding a majority of low energy highly ordered structures featuring a large fraction of vertices and edges surface atoms. Moreover the crystallization of the Au NCs structures likely occurs more easily in the gas phase where Au clusters are free from any gas or support interaction. ${ }^{[65]}$ The dispersion of these naked clusters is preserved upon soft landing on the FTO surface. The high stability of these (quasi)crystalline structures make them resistant to oxidation during the $\mathrm{CV}$ scans avoiding their deactivation by surface restructuring.

\section{Conclusion}




\section{WILEY-VCH}

In this work, we have used the CBD approach to design a novel MEO catalyst based on highly dispersed $3 \mathrm{~nm}$ zero valence deposited Au clusters that exhibit exceptional mass and specific activity of $329 \mu{\mathrm{A} \mu \mathrm{g}^{-1} \mathrm{Au} \text { and } 2 \mathrm{~mA} \mathrm{~cm}}^{-2}$ respectively, at MEO potential of $160 \mathrm{mV}$ (vs SCE at $20 \mathrm{mV} \mathrm{s}^{-1}$ ). The enhanced activity of nanoclustered Au is tied by DFT to the high density of highly active under-coordinated edge and vertex surface Au atoms resulting from the faceted geometries of the Au clusters deposited on FTO by CBD. These Au atoms strongly bind CO and $\mathrm{OH}$ enhancing the interaction with methanol, while high dispersion and stability of the cluster (quasi)crystalline structure prevents their destructive oxidation. We anticipate that this work further motivates the rational design of high performance Au based electrocatalysts that could replace Pt as fuel cell catalyst.

\section{Acknowledgements}

The research leading to these results has received funding from the European Union's Seventh Framework Programme (FP7/2007-2013) under grant agreement No. 607417 (Catsense), KU Leuven Research Council (CELSA/18/032), the Flemish Hercules Stichting (AKUL/13/19), and National Natural Science Foundation of China (No. 11904411). The authors thank Dr. Maarten Nachtegaal and staff of the SuperXAS beamline, at the Swiss Light Source, Switzerland for providing the beamtime and for their assistance in the XAS measurements. We are also grateful to Dr. Qiang Zhao for the RBS measurements and Prof. Jin Won Seo (KU Leuven) for assistance in STEM. We gratefully acknowledge Ran Duan from the School of Material Science and Engineering, Central South University, Changsha, China for his assistance in optimizing the synthesis of Au colloids. A.Y. and Y.L. initiated the study and 


\section{WILEY-VCH}

417 contributed equally to this manuscript. A.Y. and T.W.L. prepared the CBD samples. Y.L.

418 synthesized the colloidal Au samples and performed the electrochemical study. K.J.H. and A.Y.

419 performed STEM measurements. O.V.S, D.G., A.Y., and T.W.L performed the XAFS

420 measurement. J.E.S. performed SEM imaging. T.H. performed the DFT calculations. P.L. and

421 E.J. managed the study. A.Y. and D.G. coordinated the writing of the paper with contributions 422 of all co-authors.

423 


\section{WILEY-VCH}

\section{References}

[1] P. Joghee, J. N. Malik, S. Pylypenko, R. O’Hayre, MRS Energy \& Sustainability 2015, 2, E3.

[2] G. A. Olah, A. Goeppert, G. K. S. Prakash, Beyond Oil and Gas: The Methanol Economy, 2011; G. A. Olah, A. Goeppert, G. K. S. Prakash, The Journal of Organic Chemistry 2009, $74,487$.

[3] A. Kongkanand, M. F. Mathias, The Journal of Physical Chemistry Letters 2016, 7, 1127; A. Ganesan, M. Narayanasamy, Materials for Renewable and Sustainable Energy 2019, 8, 18; L. Chong, J. Wen, J. Kubal, F. G. Sen, J. Zou, J. Greeley, M. Chan, H. Barkholtz, W. Ding, D.-J. Liu, Science 2018, 362, 1276.

[4] F. Jing, R. Sun, S. Wang, H. Sun, G. Sun, Energy \& Fuels 2020, 34, 3850; S. D. Knights, K. M. Colbow, J. St-Pierre, D. P. Wilkinson, Journal of Power Sources 2004, 127, 127.

[5] Y. Tong, X. Yan, J. Liang, S. X. Dou, Small 2019, n/a, 1904126; Q. Sun, H. Xu, Y. Du, ChemSusChem 2020, 13, 2540.

[6] W. Huang, H. Wang, J. Zhou, J. Wang, P. N. Duchesne, D. Muir, P. Zhang, N. Han, F. Zhao, M. Zeng, J. Zhong, C. Jin, Y. Li, S.-T. Lee, H. Dai, Nature Communications 2015, 6, 10035; J. S. Spendelow, A. Wieckowski, Physical Chemistry Chemical Physics 2007, 9, 2654.

[7] L. Xing, G. Jerkiewicz, D. Beauchemin, Analytica Chimica Acta 2013, 785, 16; S. Cherevko, N. Kulyk, K. J. J. Mayrhofer, Nano Energy 2016, 29, 275.

[8] R. Borup, J. Meyers, B. Pivovar, Y. S. Kim, R. Mukundan, N. Garland, D. Myers, M. Wilson, F. Garzon, D. Wood, P. Zelenay, K. More, K. Stroh, T. Zawodzinski, J. Boncella, J. E. McGrath, M. Inaba, K. Miyatake, M. Hori, K. Ota, Z. Ogumi, S. Miyata, A. Nishikata, Z. Siroma, Y. Uchimoto, K. Yasuda, K.-i. Kimijima, N. Iwashita, Chemical Reviews 2007, 107, 3904.

[9] P. Rodriguez, M. T. M. Koper, Phys Chem Chem Phys 2014, 16, 13583; S. Cosentino, G. Fiaschi, V. Strano, K.-j. Hu, T.-W. Liao, N. M. Hemed, A. Yadav, S. Mirabella, D. Grandjean, P. Lievens, Y. Shacham-Diamand, The Journal of Physical Chemistry C 2017, 121, 15644; B. Liu, H. Yao, W. Song, L. Jin, I. M. Mosa, J. F. Rusling, S. L. Suib, J. He, J Am Chem Soc 2016, 138, 4718; S. Pedireddy, H. K. Lee, W. W. Tjiu, I. Y. Phang, H. R. Tan, S. Q. Chua, C. Troadec, X. Y. Ling, Nat Commun 2014, 5, 4947; H. Xia, Y. Ran, H. Li, X. Tao, D. Wang, J Mater Chem A 2013, 1, 4678; Y. Qin, Y. Song, N. Sun, N. Zhao, M. Li, L. Qi, Chem Mater 2008, 20, 3965; Y. Song, T. Miao, P. Zhang, C. Bi, H. Xia, D. Wang, X. Tao, Nanoscale 2015, 7, 8405.

[10] J. Hernández, J. Solla-Gullón, E. Herrero, A. Aldaz, J. M. Feliu, Electrochimica Acta 2006, 52, 1662.

[11] J. Zhang, P. Liu, H. Ma, Y. Ding, The Journal of Physical Chemistry C 2007, 111, 10382.

[12] G. Tremiliosi-Filho, E. R. Gonzalez, A. J. Motheo, E. M. Belgsir, J. M. Léger, C. Lamy, J Electroanal Chem 1998, 444, 31.

[13] Z. Wang, J. Du, Y. Zhang, J. Han, S. Huang, A. Hirata, M. Chen, Nano Energy 2019, 56, 286.

[14] K. A. Assiongbon, D. Roy, Surface Science 2005, 594, 99.

[15] P. Santhosh, A. Gopalan, K.-P. Lee, J Catal 2006, 238, 177.

[16] S. Yan, S. Zhang, Y. Lin, G. Liu, The Journal of Physical Chemistry C 2011, 115, 6986.

[17] W. Zhu, R. Michalsky, Ö. Metin, H. Lv, S. Guo, C. J. Wright, X. Sun, A. A. Peterson, S. Sun, J Am Chem Soc 2013, 135, 16833.

[18] S. Back, M. S. Yeom, Y. Jung, Acs Catal 2015, 5, 5089.

[19] N. Lopez, T. V. W. Janssens, B. S. Clausen, Y. Xu, M. Mavrikakis, T. Bligaard, J. K. Nørskov, Journal of Catalysis 2004, 223, 232. 


\section{WILEY-VCH}

481

482

483

484

485

486

487

488

489

490

491

492

493

494

495

496

497

498

499

500

501

502

503

504

505

506

507

508

509

510

511

512

513

514

515

516

517

518

519

520

521

522

523

524

525

526

527

528

529

530

531

[20] M. Haruta, Nature 2005, 437, 1098; H. Tsunoyama, H. Sakurai, Y. Negishi, T. Tsukuda, J Am Chem Soc 2005, 127, 9374; M. Haruta, Catal Today 1997, 36, 153; A. S. K. Hashmi, G. J. Hutchings, Angew Chem Int Edit 2006, 45, 7896; S. Ye, A. P. Brown, A. C. Stammers, N. H. Thomson, J. Wen, L. Roach, R. J. Bushby, P. L. Coletta, K. Critchley, S. D. Connell, A. F. Markham, R. Brydson, S. D. Evans, Advanced Science 2019, 6, 1900911; J. J. Gooding, Chemistry - A European Journal 2019, 25, 5335; R. Ciriminna, E. Falletta, C. Della Pina, J. H. Teles, M. Pagliaro, Angewandte Chemie International Edition 2016, 55, 14210; G. Malta, S. A. Kondrat, S. J. Freakley, C. J. Davies, L. Lu, S. Dawson, A. Thetford, E. K. Gibson, D. J. Morgan, W. Jones, P. P. Wells, P. Johnston, C. R. A. Catlow, C. J. Kiely, G. J. Hutchings, Science 2017, 355, 1399.

[21] M. Comotti, C. Della Pina, R. Matarrese, M. Rossi, Angewandte Chemie International Edition 2004, 43, 5812.

[22] M. Valden, X. Lai, D. W. Goodman, Science 1998, 281, 1647; M. Valden, S. Pak, X. Lai, D. W. Goodman, Catal Lett 1998, 56, 7; G. R. Bamwenda, S. Tsubota, T. Nakamura, M. Haruta, Catal Lett 1997, 44, 83; M. Haruta, Physics and Chemistry of Clusters 2001, 117 , 99.

[23] S. Guerin, B. E. Hayden, D. Pletcher, M. E. Rendall, J.-P. Suchsland, Journal of Combinatorial Chemistry 2006, 8, 679.

[24] W. Tang, H. Lin, A. Kleiman-Shwarsctein, G. D. Stucky, E. W. McFarland, The Journal of Physical Chemistry C 2008, 112, 10515.

[25] Y. Xu, M. Mavrikakis, The Journal of Physical Chemistry B 2003, 107, 9298; N. Lopez, J. K. Nørskov, J Am Chem Soc 2002, 124, 11262.

[26] G. C. Bond, Molecules 2012, 17, 1716.

[27] N. Saliba, D. H. Parker, B. E. Koel, Surf Sci 1998, 410, 270.

[28] A. R. Poerwoprajitno, L. Gloag, S. Cheong, J. J. Gooding, R. D. Tilley, Nanoscale 2019, $11,18995$.

[29] M. Okumura, T. Akita, M. Haruta, Catal Today 2002, 74, 265; H. Li, Z. Li, Y. Yu, Y. Ma, W. Yang, F. Wang, X. Yin, X. Wang, The Journal of Physical Chemistry C 2017, $121,12071$.

[30] C. Zeng, Y. Chen, K. Kirschbaum, K. J. Lambright, R. Jin, Science 2016, 354, 1580.

[31] Z. Li, H.-Y. T. Chen, K. Schouteden, T. Picot, T.-W. Liao, A. Seliverstov, C. Van Haesendonck, G. Pacchioni, E. Janssens, P. Lievens, Science Advances 2020, 6, eaay4289; T.-W. Liao, A. Yadav, P. Ferrari, Y. Niu, X.-K. Wei, J. Vernieres, K.-J. Hu, M. Heggen, R. E. Dunin-Borkowski, R. E. Palmer, K. Laasonen, D. Grandjean, E. Janssens, P. Lievens, Chemistry of Materials 2019, 31, 10040; T. W. Liao, A. Yadav, K. J. Hu, J. van der Tol, S. Cosentino, F. D'Acapito, R. E. Palmer, C. Lenardi, R. Ferrando, D. Grandjean, P. Lievens, Nanoscale 2018, 10, 6684; A. Yadav, R. Pandey, T.-W. Liao, V. S. Zharinov, K.-J. Hu, J. Vernieres, R. E. Palmer, P. Lievens, D. Grandjean, Y. Shacham-Diamand, Nanoscale 2020, 12, 6047.

[32] S. R. Plant, L. Cao, R. E. Palmer, J Am Chem Soc 2014, 136, 7559.

[33] Z. W. Wang, R. E. Palmer, Nanoscale 2012, 4, 4947.

[34] Z. W. Wang, R. E. Palmer, Nano Lett 2012, 12, 5510.

[35] Z. Y. Li, N. P. Young, M. Di Vece, S. Palomba, R. E. Palmer, A. L. Bleloch, B. C. Curley, R. L. Johnston, J. Jiang, J. Yuan, Nature 2008, 451, 46.

[36] Z. W. Wang, R. E. Palmer, Phys Rev Lett 2012, 108.

[37] Y. Negishi, Y. Takasugi, S. Sato, H. Yao, K. Kimura, T. Tsukuda, Journal of the American Chemical Society 2004, 126, 6518; T. Higaki, Y. Li, S. Zhao, Q. Li, S. Li, X.S. Du, S. Yang, J. Chai, R. Jin, Angewandte Chemie International Edition 2019, 58, 8291; X. Du, R. Jin, ACS Nano 2019, 13, 7383.

[38] T.-W. Liao, A. Yadav, K.-J. Hu, J. van der Tol, S. Cosentino, F. D'Acapito, R. E. Palmer, C. Lenardi, R. Ferrando, D. Grandjean, P. Lievens, Nanoscale 2018, 10, 6684. 


\section{WILEY-VCH}

[39] M. Giorgetti, G. Aquilanti, B. Ballarin, M. Berrettoni, M. C. Cassani, S. Fazzini, D. Nanni, D. Tonelli, Analytical Chemistry 2016, 88, 6873; S.-Y. Chang, A. Uehara, S. G. Booth, K. Ignatyev, J. F. W. Mosselmans, R. A. W. Dryfe, S. L. M. Schroeder, RSC Advances 2015, 5, 6912.

[40] R. E. Benfield, Journal of the Chemical Society, Faraday Transactions 1992, 88, 1107; N. S. Marinković, K. Sasaki, R. R. Adžić, Zaštita materijala 2016, 57, 101.

[41] J. T. Miller, A. J. Kropf, Y. Zha, J. R. Regalbuto, L. Delannoy, C. Louis, E. Bus, J. A. van Bokhoven, J Catal 2006, 240, 222; R. E. Benfield, D. Grandjean, M. Kröll, R. Pugin, T. Sawitowski, G. Schmid, The Journal of Physical Chemistry B 2001, 105, 1961.

[42] A. Chen, J. Lipkowski, The Journal of Physical Chemistry B 1999, 103, 682.

[43] J. Luo, P. N. Njoki, Y. Lin, D. Mott, L. Y. Wang, C. J. Zhong, Langmuir 2006, 22, 2892; A. Kowal, M. Li, M. Shao, K. Sasaki, M. B. Vukmirovic, J. Zhang, N. S. Marinkovic, P. Liu, A. I. Frenkel, R. R. Adzic, Nat Mater 2009, 8, 325.

[44] A. Hamelin, J Electroanal Chem 1996, 407, 1.

[45] Z. Borkowska, A. Tymosiak-Zielinska, G. Shul, Electrochim Acta 2004, 49, 1209; M. Avramov-Ivić, V. Jovanović, G. Vlajnić, J. Popić, J Electroanal Chem 1997, 423, 119.

[46] B. Ni, P. He, W. Liao, S. Chen, L. Gu, Y. Gong, K. Wang, J. Zhuang, L. Song, G. Zhou, X. Wang, Small 2018, 14, 1703749.

[47] M. Graf, M. Haensch, J. Carstens, G. Wittstock, J. Weissmüller, Nanoscale 2017, 9, 17839.

[48] Z. Borkowska, A. Tymosiak-Zielinska, R. Nowakowski, Electrochim Acta 2004, 49, 2613.

[49] W. Ye, H. Kou, Q. Liu, J. Yan, F. Zhou, C. Wang, International Journal of Hydrogen Energy 2012, 37, 4088.

[50] L. Y. Chen, T. Fujita, Y. Ding, M. W. Chen, Advanced Functional Materials 2010, 20, 2279; X.-J. Huang, D. S. Silvester, I. Streeter, L. Aldous, C. Hardacre, R. G. Compton, The Journal of Physical Chemistry C 2008, 112, 19477.

[51] Z. Mao, H. Hu, R. Su, P. Liu, Y. Li, W. Zhang, X. Zhao, J. Guo, P. Guan, G. Qin, X. Zhang, ChemCatChem 2018, 10, 141.

[52] M. A. Schneeweiss, D. M. Kolb, Solid State Ionics 1997, 94, 171.

[53] R. J. Nichols, O. M. Magnussen, J. Hotlos, T. Twomey, R. J. Behm, D. M. Kolb, Journal of Electroanalytical Chemistry and Interfacial Electrochemistry 1990, 290, 21.

[54] W. Polewska, C. M. Vitus, B. M. Ocko, R. R. Adzic, J Electroanal Chem 1994, 364, 265.

[55] S. Yan, L. Gao, S. Zhang, L. Gao, W. Zhang, Y. Li, International Journal of Hydrogen Energy 2013, 38, 12838.

[56] S. Pedireddy, H. K. Lee, W. W. Tjiu, I. Y. Phang, H. R. Tan, S. Q. Chua, C. Troadec, X. Y. Ling, Nat Commun 2014, 5, 4947.

[57] S. Lu, H. Li, J. Sun, Z. Zhuang, Nano Research 2018, 11, 2058; D. Strmcnik, M. Uchimura, C. Wang, R. Subbaraman, N. Danilovic, D. van der Vliet, A. P. Paulikas, V. R. Stamenkovic, N. M. Markovic, Nature Chemistry 2013, 5, 300; R. Subbaraman, D. Tripkovic, K.-C. Chang, D. Strmcnik, A. P. Paulikas, P. Hirunsit, M. Chan, J. Greeley, V. Stamenkovic, N. M. Markovic, Nature Materials 2012, 11, 550; Y. Shen, Z. Zhang, R. Long, K. Xiao, J. Xi, ACS Applied Materials \& Interfaces 2014, 6, 15162; T. Liu, C. Li, Q. Yuan, ACS Omega 2018, 3, 8724.

[58] T. Cheng, Y. Huang, H. Xiao, W. A. Goddard, The Journal of Physical Chemistry Letters 2017, 8, 3317; Y. Chen, Y. Huang, T. Cheng, W. A. Goddard, Journal of the American Chemical Society 2019, 141, 11651.

[59] Y. Wang, S. Teitel, C. Dellago, The Journal of Chemical Physics 2005, 122, 214722.

[60] P. Ferrin, A. U. Nilekar, J. Greeley, M. Mavrikakis, J. Rossmeisl, Surface Science 2008, $602,3424$.

[61] G. A. Tritsaris, J. Rossmeisl, The Journal of Physical Chemistry C 2012, 116, 11980. 


\section{WILEY-VCH}

[62] J. K. Nørskov, J. Rossmeisl, A. Logadottir, L. Lindqvist, J. R. Kitchin, T. Bligaard, H. Jónsson, The Journal of Physical Chemistry B 2004, 108, 17886.

[63] E. Gonzalez Hernan, C. Alonso, J. Gonzalez-Velasco, Journal of Applied Electrochemistry $1987,17,868$.

[64] A. Howard, C. E. J. Mitchell, R. G. Egdell, Surf Sci 2002, 515, L504; M. Di Vece, D. Grandjean, M. J. Van Bael, C. P. Romero, X. Wang, S. Decoster, A. Vantomme, P. Lievens, Phys Rev Lett 2008, 100; M. Wanner, R. Werner, D. Gerthsen, Surf Sci 2006, $600,632$.

[65] F. Baletto, Journal of Physics: Condensed Matter 2019, 31, 113001. 


\section{WILEY-VCH}

\section{Abstract Graphics}

595

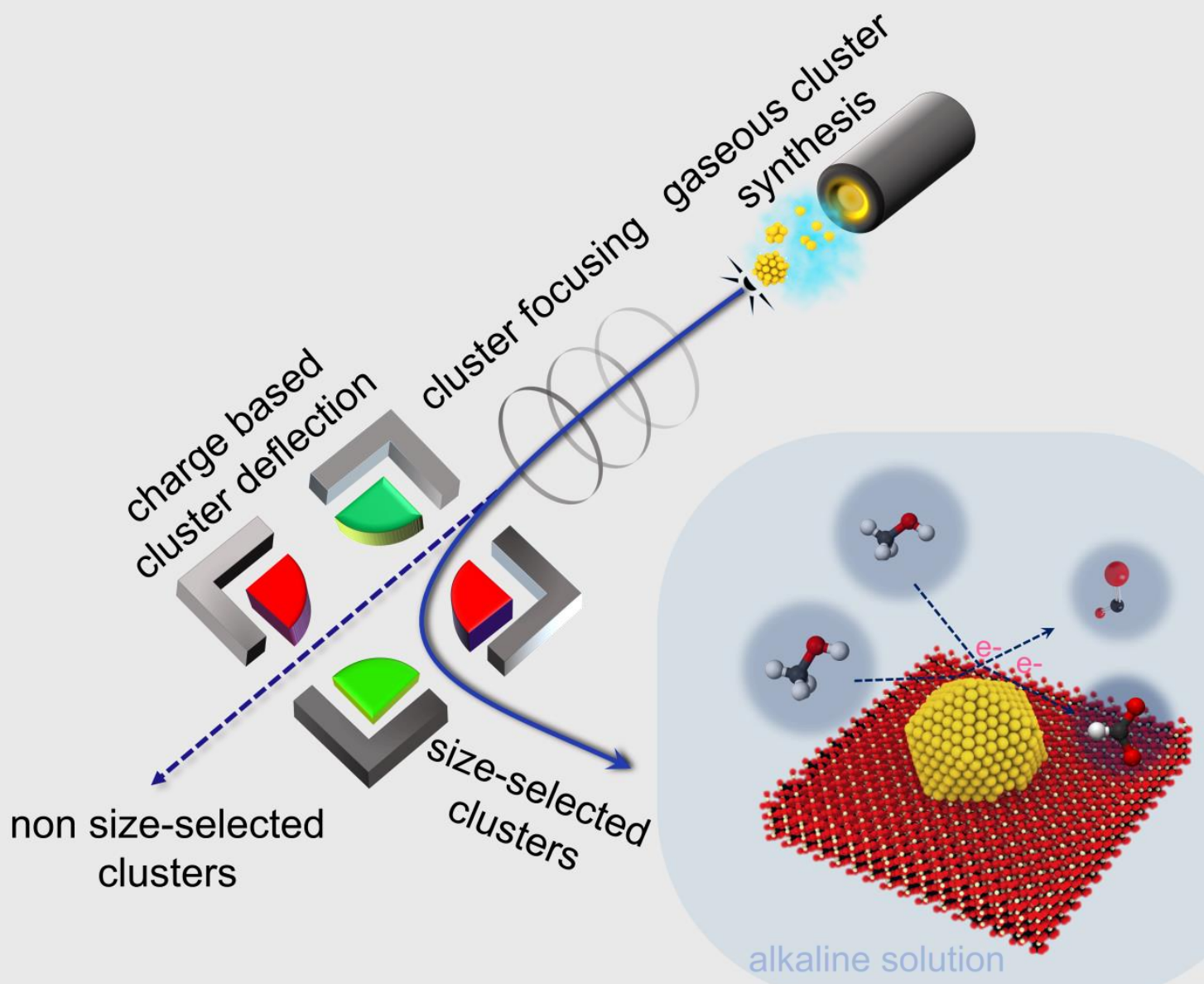

Methanol electro-oxidation with nanoclustered gold 


\section{WILEY-VCH}

598

599

Cover Art

600

Enhanced methanol electro oxidation by nanoclustered gold

601

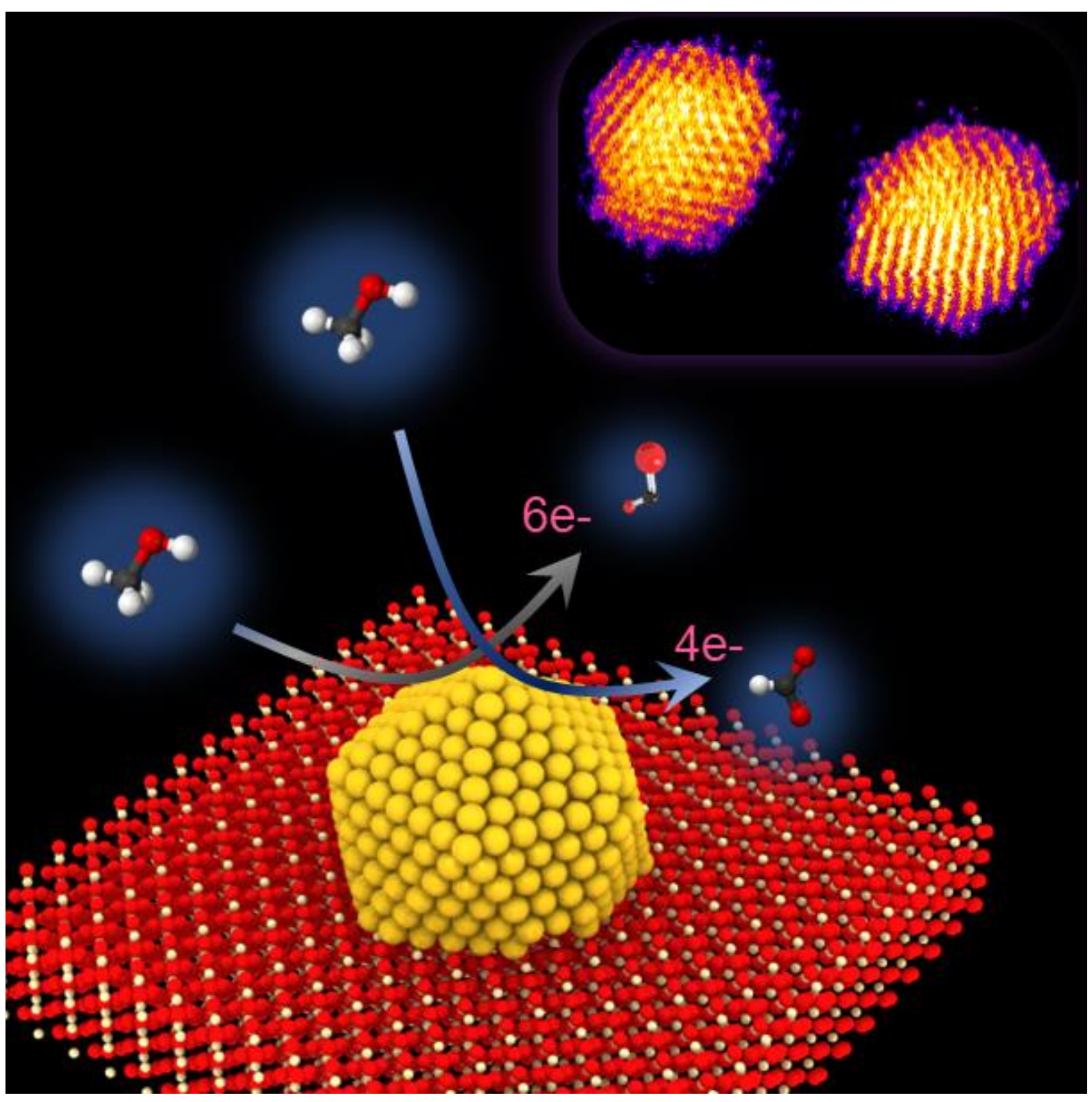

602 